\title{
Soft tissue tumors and tumor-like lesions of the fingers
}

\begin{abstract}
The purpose of our study, was to look for the soft tissue lesions that took place in the fingers; starting from the metacarpo-phalangeal joints proximally, including the web space, to the tip of the fingers. Various tumors and non-neoplastic, tumor-like lesions occur in the upper extremity. Some are common whereas others are very rare. Such lesions occurring in the hand and wrist have been evaluated in multiple studies in the literature.
\end{abstract}

Methods: Lesions were collected from the patients who were presented to our orthopedic section, complaining of tumors in their hands. Those with lesions limited to the fingers were only included. All lesions were evaluated clinically and radiologically, and were extracted by complete excision, and histopathologically analyzed.

Results: There were 35 cases; 21 male and 14 female patients with age range of 7 to 66 years Average age range in the male group was $41.2 \pm 14.1$, and in the female group $37.4 \pm 7.3$. All were benign lesions. The three most common lesions found were; giant cell tumor of the tendon sheath, epidermoid inclusion cyst and ganglion of the tendon sheath, in this order. The follow up ranged from 2 to 5years (average 3.5years). No recurrence was reported.

Conclusion: The frequency of the lesions in the fingers was different from their frequency in the hand and wrist in comparison with other studies. In spite of the high probability of benignity, a proper history and clinical examination are essential. Plain radiographs are preferably requested, but advanced imaging modalities are rarely needed preoperatively. The type of this study is diagnostic with level of evidence IV.

Keywords: hand soft tissue tumors, hand tumor-like lesions, finger nodules, and masson's tumor
Volume 10 Issue $3-2018$

\section{Eyad G Al-Maqdassy}

This Study was conducted in the Department of Surgery, Hamad General Hospital, in Hamad Medical Corporation, Doha, Qatar

Correspondence: Eyad G Al-Maqdassy, Email eyadmaqdassy@yahoo.co.uk

Received: April 20, 2017| Published: June 25, 2018
Abbreviations: GCT, giant cell tumors; IPEH, intravascular papillary endothelial hyperplasia; MRI, magnetic resonance imaging; CT, computed tomography

\section{Introduction}

Tumors of the hand are very common, with the majority being benign lesions; moreover, because the types of cell structures existing within the hand vary widely, the cellular origins of the tumors also vary. ${ }^{1,2}$ Lesions of the hand may originate in either soft tissues or bone. Soft tissue tumors of the hand arise from skin, subcutaneous tissue, tendons, nerve, and blood vessels and can be divided into pseudotumors (non-neoplastic enlargements) and true benign and malignant neoplasms, and the majority of soft tissue hand tumors are benign with very few malignant lesions. ${ }^{1-4}$ Metastatic tumors to the hand are extremely rare and the majorities are metastases to the bone from carcinoma of the lung. ${ }^{2}$ The three most common soft-tissue masses (tumors and tumor-like lesions) on the hand; are ganglions (including mucous cysts), giant cell tumors of the tendon sheath (GCT), and epidermal inclusion cysts. ${ }^{1-6}$ No age group is exempt from tumors in the hand, and certain tumors show a peculiar tendency to develop predominantly in the hand, like glomus tumors, ganglia, implantation cysts, isolated xanthomas and giant cell tumors of the tendon sheath. ${ }^{7}$ This study presents the clinical and pathological findings for 35 patients with soft tissue tumors and non-neoplastic tumor-like lesions of the fingers, in order to determine the relative frequency of these lesions.

\section{Materials and methods}

All the patients presented to our orthopedic unit within five years, complaining of soft tissue nodules or masses situated in the area of the fingers (from the metacarpo-phalangeal joints towards the finger tips), were included. Approval was granted by the Institutional Review Board of our hospital, and consents to enroll into this study were taken from the patients. Criteria for exclusion were; pyogenic inflammation, recurrent lesions, or lesions originating from the bone. Thirty-five patients were included: 21 males $(60 \%)$ and 14 females $(40 \%)$. Age range was 7 to 66years (mean age 41.2 \pm 14.1 ) in the male group, and 25 to 50 years (mean age $37.4 \pm 7.3$ ) in the female group. The overall mean age was $39.7 \pm 11.8$. This difference in the mean age between the two groups is statistically insignificant $(\rho=0.364)$.

The patients were questioned regarding the history of the lesion, and this information was recorded. All the patients were clinically examined for the following: the exact location of the tumor, its connection to the skin or underlying tissues, pain and tenderness, skin discoloration, texture and effect on the range of motion of the affected finger. Plain radiographs of the hand were obtained for all the patients, to identify whether the lesion is osseous or extra-osseous; no other imaging modality was indicated based on the clinical findings and the management plan. All the lesions were treated by excisional biopsy (marginal excision) under general anaesthesia or regional block using standards skin incisions whenever possible, and a tourniquet was used to facilitate meticulous dissection. The lesions did not require intra-operative biopsy with frozen section, because in addition to 
the high degree of probability that all were benign, they were well circumscribed and easily isolated from the surrounding tissues and easy to excise in Toto. Follow up ranged from 2 to 5years (average 3.5years).

\section{Results}

Different types of benign lesions were found our patients. No malignancy was recorded. The results are tabulated according to their relative frequencies in Table 1. The most common lesion was the giant cell tumor of the tendon sheath, followed by the epidermoid inclusion cysts, ganglion of the tendon sheath and the nerve sheath tumors. An interesting finding was the presence of Masson's tumor (Masson's vegetant intravascular hemangioendothelioma, or intravascular papillary endothelial hyperplasia [IPEH]). All the lesions were relatively small in size ranging from $0.4 \mathrm{~cm}$ to $1.2 \mathrm{~cm}$ at their greatest diameter.

Table I Soft tissue tumors of the fingers

\begin{tabular}{lll}
\hline DIAGNOSIS & $\begin{array}{l}\text { Number of } \\
\text { cases }\end{array}$ & Percentage \\
\hline $\begin{array}{l}\text { Giant cell tumors of tendon } \\
\text { sheath }\end{array}$ & 8 & $22.85 \%$ \\
Epidermoid inclusion cysts & 6 & $17.14 \%$ \\
$\begin{array}{l}\text { Ganglion of tendon sheath } \\
\text { Neurilemmoma }\end{array}$ & 5 & $14.28 \%$ \\
$\begin{array}{l}\text { Schwannoma) } \\
\text { Cavernous haemangioma }\end{array}$ & 2 & $11.42 \%$ \\
$\begin{array}{l}\text { Angioleiomyoma } \\
\text { Blood clot (organizing } \\
\text { thrombus) }\end{array}$ & $\mathrm{I}$ & $5.71 \%$ \\
Fibromatosis & $\mathrm{I}$ & $2.85 \%$ \\
Keratoacanthoma & $\mathrm{I}$ & $2.85 \%$ \\
Masson's tumor & $\mathrm{I}$ & $2.85 \%$ \\
Neurofibroma & $\mathrm{I}$ & $2.85 \%$ \\
Nodular fasciitis & $\mathrm{I}$ & $2.85 \%$ \\
Lipoma & $\mathrm{I}$ & $2.85 \%$ \\
Rheumatoid nodule & $\mathrm{I}$ & $2.85 \%$ \\
Vascular malformation & 35 & $2.85 \%$ \\
\hline $\begin{array}{l}\text { Total } \\
\text { I }\end{array}$ & & $2.85 \%$ \\
\hline
\end{tabular}

The duration of presentation of the patients was so variable, ranging from 3 months to 20years. Ten of the patients could not recollect when the lesions were first detected, 12 patients had the lesions for less than 1 year. A 60 -year-old patient had an epidermoid inclusion cyst for 20years, while a 7-year-old patient had a cavernous hemangioma since birth. Tenderness was not a major significant cause for urgent medical consultation, as many of the earlier patients did not experience pain or tenderness, and was not significantly related to a certain type of lesion.

Only 2patients had a history of trauma, the Masson's tumor patient and the epidermoid inclusion cyst patient.

The lesions were located on the right hand in 23 patients and on the left hand in 12patients; of these, 10 were located on the middle finger, 7 on the ring finger, 6 on the thumb, 5 on the index finger, 4 in the web spaces and 3 on the little finger. No significant relation was found between the lesions and their location. The dominant hand was not a part of the survey. No recurrences or any complications related to the lesions or the surgical procedures were recorded in the follow up.

\section{Discussion}

A variety of tumors and non-neoplastic tumor-like soft tissue lesions can occur in the upper extremities; some are common, whereas others are rare. A careful history, physical examination, and various imaging modalities can help ensure accurate tumor management. ${ }^{6}$ Many types of cell structures that exist within the hand contribute to the broad spectrum of hand tumors, and tumors of various cellular origins can thus be identified, most which are benign. ${ }^{1-3}$ The lesions can be divided into two groups; tumorlike lesions and true neoplasms; the latter group is subdivided into benign and malignant tumors. ${ }^{5}$ Tumors of the hand can be classified according to the tissue of origin: the epidermis, dermis, sweat glands, fat, fascia, vessels, nerves, muscles, and bone. ${ }^{7}$ Most of these tumors occur as a small lump or nodule, which may or may not be painful. ${ }^{1}$ In our series, only 7 patients complained of pain or tenderness; however, this feature was not characteristic of any particular lesion. Clinical diagnosis may be uncertain because of the proximity of many different tissues in a small area; therefore, a histological diagnosis is necessary to ensure appropriate treatment. ${ }^{8}$ Currently, imaging modalities that are most commonly used for hand, wrist, and forearm are plain radiography, magnetic resonance imaging (MRI), and ultrasound, whereas the use of computed tomography (CT) and nuclear imaging is limited. ${ }^{9}$ Plain radiography is useful in locating any bony involvements; either secondary to the soft tissue mass, or an original bone lesion that had extended to the surrounding soft structures. In the keratoacanthoma patient in our series, a bony indentation in the adjacent phalanx was found on radiography. Some authors believe that MRI is very useful for preliminary examination and predictive diagnosis of tumors and pseudotumors of the hand. ${ }^{9,10}$ Three articles dealing with digit lesions were found in the literature; the first article is a case report concerned with one histologic variety only, which is primary GCT of the soft tissue in the ring finger. ${ }^{11}$ The second article reported 21 cases of patients with fibro-osseous pseudotumors occurring in the soft tissue of the digits; of these, 20cases were of finger lesions and 1case was of a toe lesion. ${ }^{12}$ The third article reported 4 cases of epidermoid inclusion cysts in the terminal phalanges. ${ }^{13}$ In our series, 4 categories of lesions $(68.54 \%)$ constituted most of the cases; the most common category was the GCT of the tendon sheath $(22.85 \%)$, followed by the epidermoid inclusion cysts (17.14\%), ganglion of the tendon sheath (14.28\%), and the nerve sheath tumors (14.27\%). In Palmieri's study, ${ }^{1}$ the ganglions were most frequently reported $(60 \%)$, followed by the GCT of the tendon sheath (13\%), and the epidermoid inclusion cysts $(8 \%)$. A similar frequency was observed in the studies by Sobanko et al., ${ }^{4}$ Plate et al., ${ }^{5}$ and Nahra and Bucchieri. ${ }^{14}$ The studies by Lucas, ${ }^{15}$ and Johnson et al., ${ }^{16}$ had different incidence rates of the tumors of the hand, the frequency of ganglions was the highest, followed by the epidermoid inclusion cysts and GCT of the tendon sheath.

The results reported by Bogumill et al., ${ }^{8}$ differed greatly in terms of frequency. In the 129 cases collected from the hand and wrist tumors in the study, the commonest were ganglions (71 cases); followed by GCT of the tendon sheath (13cases), and only 2 cases of epidermoid inclusion cysts which were ninth in order of frequency. The prevalence of ganglion cysts in other studies addressing lesions of the hand is explained by the fact that $68-90 \%$ of them occur in 
the wrist joint, ${ }^{1,5,6,14}$ which together with the metacarpal region were excluded in our study.

An interesting finding in our series was that of one case of Masson's tumor in the subcutaneous layer of the volar surface of the proximal phalanx of the ring finger in a 35-year old man who had a history of trauma six months before presentation. In 1923, Pierre Masson first described this type of lesion; he regarded it as a true benign neoplasm, and termed it as a vegetant intravascular hemangioendothelioma. ${ }^{17}$ Over the years, various names have been used to describe the lesion, such as intravascular angiomatosis, intravenous vascular proliferation, Masson's pseudoangiosarcoma, and Masson's tumor. ${ }^{18}$ In 1976, Clerkin et al., ${ }^{19}$ first proposed the descriptive term intravascular papillary endothelial hyperplasia (IPEH) by which the lesion is best known today. IPEH is a relatively rare lesion that occurs in the fingers, head and neck, trunk, lower extremities, and upper extremities; however, its frequency in terms of location has been found to fluctuate in different articles. ${ }^{19,20}$ In 1985, Marwan et al., ${ }^{21}$ reported a case of IPEH in the ring finger of a 55-year old man, and in their literature review, they collected 94cases of Masson's tumor in which it showed no age or sex predilection, but had a higher frequency in the head and neck followed by the hand. Owing to the ability of Masson's tumor to simulate the growth pattern of a malignant vascular tumor, the histologic distinction between this lesion and the tuft-like structures of a hemangiosarcoma may be exceedingly difficult. ${ }^{18,22}$ The relatively small number of cases obtained in this study was mainly due to its nature and design in limiting the collected lesions from the fingers only.

\section{Summary}

In summary, a thorough history, physical examination, and plain radiography of the affected area are the basic requirements for managing such lesions. Other advanced imaging modalities, primarily MRI, are required in cases where these findings indicate a clinical suspicion of malignancy.

\section{Acknowledgements}

None.

\section{Conflict of interest}

The author declares no conflict of interest.

\section{References}

1. Palmieri TJ. Common tumors of the hand. Orthop Rev. 1987;16(6):367378.

2. Schultz RJ, Kearns RJ. Tumors in the hand. J Hand Surg. 1983;8A:803806.

3. Ingari JV, Faillace JJ. Benign tumors of fibrous tissue and adipose tissue in the hand. Hand Clin. 2004;20(3):243-248.
4. Sobanko JF, Dagum AB, Davis IC, et al. Soft tissue tumors of the hand. 1. Benign. Dermatol Surg. 2007;33(6):651-667.

5. Plate AM, Lee SJ, Steiner G, et al. Tumorlike lesions and benign tumors of the hand and wrist. J Am Acad Orthop Surg. 2003;11(2):129-141.

6. Shapiro PS, Seitz WH. Non-neoplastic tumors of the hand and upper extremity. Hand Clin. 1995;11(2):133-160.

7. Shenaq SM. Benign skin and soft-tissue tumors of the hand. Clin Plast Surg. 1987;14(2):403-412.

8. Bogumill GP, Sullivan DJ, Baker GI. Tumors of the hand. Clin Orthop Relat Res. 1975;108:214-222.

9. Lindequist S, Marelli C. Modern imaging of the hand, wrist, and forearm. J Hand Ther. 2007;20(2):119-131.

10. Capelastegui A, Astigarraga E, Fernandez G, et al. Masses and pseudomasses of the hand and wrist: MR findings in 134 cases. Skeletal Radiol. 1999;28(9):498-507.

11. Vaquerizo AT, Molina IR, Serrano TG, et al. Primary giant cell tumor of soft tissue in the finger. Dermatology Online J. 2008;14(6):7

12. Dupree WB, Enzinger FM. Fibro-osseous pseudotumor of the digits. Cancer. 1986;58:2103-2109.

13. Byers P, Mantle J, Salm R. Epidermal cysts of phalanges. J Bone Joint Surg. 1966;48(3):577-581.

14. Nahra ME, Bucchieri JS. Ganglion cysts and other tumor related conditions of the hand and wrist. Hand Clin. 2004;20(3):249-260.

15. Lucas GL. Epidermoid inclusion cysts of the hand. J South Orthop Assoc. 1999;8(3):188-192.

16. Johnson J, Kilgore E, Newmeyer W. Tumorous lesions of the hand. $J$ Hand Surg. 1985;10(2):284-286.

17. Steffen C. The Man Behind the Eponym: C. L. Pierre Masson. Am J Dermatopathol. 2003;25(1):71-76.

18. Clifford PD, Temple HT, Jorda M, et al. Intravascular papillary endothelial hyperplasia (Masson's tumor) presenting as a triceps mass. Skeletal Radiol. 2004;33(7):421-425.

19. Clearkin KP, Enzinger FM. Intravascular papillary endothelial hyperplasia. Arch Pathol Lab Med. 1976;100(8):441-444.

20. Hashimoto H, Daimaru Y, Enjoji M. Intravascular papillary endothelial hyperplasia. A clinicopathologic study of 91 cases. Am J Dermatopathol. 1983;5(6):539-546.

21. Wehbe MA, Otto NR. Intravascular papillary endothelial hyperplasia in the hand. J Hand Surg. 1986;11A:275-279.

22. Kuo TT, Sayers CP, Rosai J. Masson's "Vegetant intravascular hemangioendothelioma:"a lesion often mistaken for angiosarcoma. study of seventeen cases located in the skin and soft tissues. Cancer. 1976;38(3):1227-1236 